\title{
Non-alcoholic steatohepatitis: A non-invasive diagnosis by analysis of exhaled breath.
}

Citation for published version (APA):

Verdam, F. J., Dallinga, J. W., Driessen, A. L. C., de Jonge, C., Moonen, E. J., van Berkel, J. B., Luijk, J., Bouvy, N. D., Buurman, W. A., Rensen, S. S. M., Greve, J. W., \& van Schooten, F. J. (2013). Nonalcoholic steatohepatitis: A non-invasive diagnosis by analysis of exhaled breath. Journal of Hepatology, 58(3), 543-548. https://doi.org/10.1016/j.jhep.2012.10.030

Document status and date:

Published: 01/03/2013

DOI:

10.1016/j.jhep.2012.10.030

Document Version:

Publisher's PDF, also known as Version of record

Document license:

Taverne

Please check the document version of this publication:

- A submitted manuscript is the version of the article upon submission and before peer-review. There can be important differences between the submitted version and the official published version of record.

People interested in the research are advised to contact the author for the final version of the publication, or visit the DOI to the publisher's website.

- The final author version and the galley proof are versions of the publication after peer review.

- The final published version features the final layout of the paper including the volume, issue and page numbers.

Link to publication

\footnotetext{
General rights rights.

- You may freely distribute the URL identifying the publication in the public portal. please follow below link for the End User Agreement:

www.umlib.nl/taverne-license

Take down policy

If you believe that this document breaches copyright please contact us at:

repository@maastrichtuniversity.nl

providing details and we will investigate your claim.
}

Copyright and moral rights for the publications made accessible in the public portal are retained by the authors and/or other copyright owners and it is a condition of accessing publications that users recognise and abide by the legal requirements associated with these

- Users may download and print one copy of any publication from the public portal for the purpose of private study or research.

- You may not further distribute the material or use it for any profit-making activity or commercial gain

If the publication is distributed under the terms of Article $25 \mathrm{fa}$ of the Dutch Copyright Act, indicated by the "Taverne" license above, 


\title{
Non-alcoholic steatohepatitis: A non-invasive diagnosis by analysis of exhaled breath
}

\author{
Froukje J. Verdam ${ }^{1,2}$, Jan W. Dallinga ${ }^{3}$, Ann Driessen ${ }^{4}$, Charlotte de Jonge ${ }^{1,2}$, Edwin J.C. Moonen ${ }^{3}$, \\ Joep B.N. van Berkel ${ }^{3}$, Jakobus Luijk ${ }^{3}$, Nicole D. Bouvy ${ }^{1}$, Wim A. Buurman ${ }^{1}$, Sander S. Rensen ${ }^{1, *}$, \\ Jan Willem M. Greve ${ }^{2}$, Frederik Jan van Schooten ${ }^{3}$ \\ ${ }^{1}$ Department of General Surgery, Nutrition and Toxicology Research Institute Maastricht (NUTRIM), Maastricht University Medical Centre, \\ Maastricht, The Netherlands; ${ }^{2}$ Department of General Surgery, Atrium Medical Centre Parkstad, Heerlen, The Netherlands; ${ }^{3}$ Department \\ of Toxicology, Nutrition and Toxicology Research Institute Maastricht (NUTRIM), Maastricht University Medical Centre, Maastricht, \\ The Netherlands; ${ }^{4}$ Department of Pathology, Maastricht University Medical Centre, Maastricht, The Netherlands
}

See Focus, pages 407-408

\begin{abstract}
Background \& Aims: Histological evaluation of a liver biopsy is the current gold standard to diagnose non-alcoholic steatohepatitis (NASH), but the procedure to obtain biopsies is associated with morbidity and high costs. Hence, only subjects at high risk are biopsied, leading to underestimation of NASH prevalence, and undertreatment. Since analysis of volatile organic compounds in breath has been shown to accurately identify subjects with other chronic inflammatory diseases, we investigated its potential as a non-invasive tool to diagnose NASH.

Methods: Wedge-shaped liver biopsies from 65 subjects (BMI $24.8-64.3 \mathrm{~kg} / \mathrm{m}^{2}$ ) were obtained during surgery and histologically evaluated. The profile of volatile organic compounds in pre-operative breath samples was analyzed by gas chromatography-mass spectrometry and related to liver histology scores and plasma parameters of alanine aminotransferase (ALT) and aspartate aminotransferase (AST).

Results: Three exhaled compounds were sufficient to distinguish subjects with $(\mathrm{n}=39)$ and without NASH $(\mathrm{n}=26)$, with an area under the ROC curve of 0.77 . The negative and positive predictive values were $82 \%$ and $81 \%$. In contrast, elevated ALT levels or increased AST/ALT ratios both showed negative predictive values of $43 \%$, and positive predictive values of $88 \%$ and $70 \%$, respectively. The breath test reduced the hypothetical percentage of undiagnosed NASH patients from $67-79 \%$ to $10 \%$, and of misdiagnosed subjects from $49-51 \%$ to $18 \%$.
\end{abstract}

Keywords: NAFLD; NASH; Obesity; Liver biopsy; Exhaled air; Volatile organic compounds.

Received 29 February 2012; received in revised form 10 October 2012; accepted 31 October 2012; available online 7 November 2012

DOI of original article: http://dx.doi.org/10.1016/j.jhep.2012.12.010.

* Corresponding author. Address: Department of Surgery, Maastricht University Medical Centre, PO Box 616, 6200 MD Maastricht, The Netherlands. Tel.: +31 433881496; fax: +31 433884154 .

E-mail address: s.rensen@maastrichtuniversity.nl (S.S. Rensen).

Abbreviations: ALT, alanine aminotransferase; AST, aspartate aminotransferase: BMI, body mass index; NAFLD, non-alcoholic fatty liver disease; NASH, non-alcoholic steatohepatitis; VOC, volatile organic compounds; $\mathrm{HbA}_{1 c}$, glycated hemoglobin; LR, likelihood ratio; PV, predictive value; GC-MS, gas chromatographymass spectrometry.
Conclusions: Analysis of volatile organic compounds in exhaled air is a promising method to indicate NASH presence and absence. In comparison to plasma transaminase levels, the breath test significantly reduced the percentage of missed NASH patients and the number of unnecessarily biopsied subjects. (c) 2012 European Association for the Study of the Liver. Published by Elsevier B.V. All rights reserved.

\section{Introduction}

Non-alcoholic fatty liver disease (NAFLD) is the most prevalent liver disease worldwide, affecting one in three adults, and one in ten adolescents in the USA [1,2]. NAFLD is present in the majority of patients with metabolic risk factors such as obesity and type 2 diabetes mellitus (T2DM) [1]. While steatosis, the early stage of NAFLD, is considered to be benign and reversible, progression towards more advanced stages often occurs. These advanced stages, referred to as non-alcoholic steatohepatitis (NASH), are characterized by inflammation $[3,4]$. Importantly, NASH is in turn associated with the development of hepatic fibrosis, cirrhosis, hepatocellular carcinoma, and an increased risk of liver failure and liver-related mortality [3,4]. It is therefore clinically relevant to differentiate between patients with sole hepatic steatosis and those suffering from NASH, at an early stage.

Currently, a liver biopsy remains necessary to accurately diagnose NASH and to assess its severity [5,6]. However, the procedure to obtain a liver biopsy is invasive and associated with considerable discomfort, costs, and morbidity; significant complications are encountered in $0.5 \%$ of cases $[7,8]$. In order to optimize the riskbenefit ratio, it is advocated to obtain a needle biopsy from all obese patients with clinical risk factors, and a per-operative biopsy from all morbidly obese patients undergoing abdominal surgery [9]. Apart from obesity, acknowledged risk factors are elevated plasma levels of alanine aminotransferase (ALT), an elevated ratio of aspartate aminotransferase (AST) to ALT (AST/ALT ratio), insulin resistance, hypertension, sleep apnea, and increased plasma levels of 


\section{Research Article}

triglycerides [10]. However, performing liver biopsy procedures based upon these risk factors leads to a selection bias in clinical practice, especially since mainly the presence of obesity and plasma levels of aminotransferases are taken into account. On the one hand, these plasma levels are often maintained within the normal range despite advanced disease [11], resulting in an underestimation of NASH prevalence, as well as undertreatment. On the other hand, if the indication to obtain a liver biopsy is based upon elevated aminotransferase levels, a large proportion of biopsies are obtained from subjects who do not suffer from NASH, since elevated AST and/or ALT levels are not specific for the presence of this liver disease.

In view of (1) the clinical relevance of NASH, (2) the difficulties of selecting the appropriate population to biopsy, and (3) the biopsy-related burden, a less invasive method to identify patients with NASH is urgently required. Such a method could be the analysis of volatile organic compounds (VOC) in exhaled breath. VOC are considered as markers of oxidative stress and can indicate the presence of reactive oxygen species that derive, for example, from peroxidation of polyunsaturated fatty acids [12]. Components in exhaled air have been previously shown to reflect the presence of inflammatory diseases affecting the airways $[13,14]$ and liver [15-17]. Hence, analysis of VOC in exhaled air may be useful for predicting NASH presence. In this pilot study, we found that subjects with NASH can be accurately distinguished from those without NASH based upon analysis of VOC in exhaled breath.

\section{Patients and methods}

\section{Study design}

Sixty-five subjects were included consecutively between October 2007 and May 2011, before they underwent laparoscopic abdominal surgery; either cholecystectomy or primary bariatric surgery. Subjects ranged from overweight to severely obese with a BMI range of $24.8-64.3 \mathrm{~kg} / \mathrm{m}^{2}$. The laparoscopic abdominal surgery was performed either at the Maastricht University Medical Centre or the Atrium Medical Centre Parkstad by the same surgeon (JWG). Exclusion criteria were acute recent, and chronic inflammatory diseases (e.g., M. Crohn, colitis), other known liver diseases (such as viral hepatitis), consumption of $>10 \mathrm{~g}$ alcohol daily, and use of medication associated with NAFLD (e.g., steroids, amiodarone, valproate, methotrexate). The previously mentioned risk factors for NASH such as BMI, hypertension, and sleep apnea were evaluated. This study was approved by the Medical Ethica Committees of both the Maastricht University Medical Centre and the Atrium Medical Centre Parkstad, and conducted according to the revised version of the Declaration of Helsinki (October 2008, Seoul). Written informed consent was obtained from all subjects.

Sample collection and analysis

Breath samples

Breath samples from all 65 patients were collected at the end of the afternoon prior to the day of the surgery. The complete analytical procedure and instrumental analysis have been published previously $[13,18]$. Briefly, all subjects exhaled into a resistance-free $5 \mathrm{~L}$ plastic bag (Tedlar bag, SKC Ltd, Dorset, UK). The VOC were trapped within $24 \mathrm{~h}$ after sampling, by deflating the bag into a sorption tube filled with carbograph 1TD/Carbopack X (Markes International Inc, Cincinnati, OH). For analysis, the VOC were released by thermal desorption and injected into a gas chromatograph (Trace GC, Thermo Fischer Scientific, Austin, TX) connected to a time-offlight mass spectrometry (Tempus Plus, Thermo Fischer Scientific) [18].

\section{Blood samples}

Preoperative fasting venous blood samples could be obtained on the morning of the surgery from 61 subjects and were processed as previously described [19]. Plasma levels of C-reactive protein (CRP), ALT, AST, glucose, insulin, total choles- terol, $\mathrm{HDL}$, LDL, triglycerides, free fatty acids and $\mathrm{HbA}_{1 \mathrm{c}}$ were measured according to the protocol of the Department of Clinical Chemistry of the Maastricht University Medical Centre. The upper limit of normal ALT levels was 35 IU/L for women and $45 \mathrm{IU} / \mathrm{L}$ for men [20], while an AST/ALT ratio $>1$ was considered to be elevated [21].

Liver biopsies

Wedge-shaped liver biopsies of at least 15 by $10 \mathrm{~mm}$ were obtained intra-operatively from all patients, by the same surgeon (JWG), and processed as previously described [22]. All biopsies contained at least five portal tracts to allow for correct evaluation of the hepatic architecture. No overt pathologic condition other than NAFLD was observed. Steatosis, hepatocellular ballooning, lobular and portal inflammation, Mallory's hyaline, and fibrosis were scored according to both the Brunt scoring system [5] and the NAS activity score according to Kleiner et al. [6], by an experienced liver pathologist (AD) blinded to the clinical context and laboratory parameters. Liver biopsies that were evaluated as healthy or steatotic did not show any sign of portal or lobular inflammation, hepatocyte ballooning, or fibrosis $(n=26)$. In contrast, livers showing signs of steatosis and inflammation were defined as NASH $(n=39)$ and were further evaluated according to the Brunt classification and NAS activity score according to Kleiner et al. [5,6].

\section{Data processing and analysis}

\section{Processing of data}

Detailed descriptions of the data handling procedures have been previously reported [18]. Briefly, gas chromatography and mass spectrometry (GC-MS) chromatograms of all breath samples were recorded. Retention times were normalized by calculating retention indices, relative to toluene and using easily recognizable component peaks, to correct for chromatographic drifting. The beginning and end of each run (retention index either $<0.15$ or $>2.8$ ) were removed because of noisy mass spectra at the beginning of the chromatograms and column bleeding at the end of each run. The remaining data, containing almost 4800 different chromatographic peaks as determined by retention time and mass spectrum combined with a relative intensity, were transformed into Excel files. The measured mass spectra were compared to one another at the same retention time. The resemblance of the original spectra determines whether or not peaks at the same retention time represent the same component. Intensities under the detection limit were set at $0 \%$.

\section{Statistical analysis of the GC-MS dato}

The data matrix was analyzed by a stepwise discriminant analysis by a leave-oneout cross-over approach, using Statistical Package for Social Sciences 19.0.0 (IBM SPSS Software Inc., Chicago, IL). All but one of the chromatograms were included to construct the discriminant function. The one that was left out was subsequently used to predict the group it belonged to. This was repeated until every chromatogram had been left out once; all samples have been classified. Based upon 33 components, the discriminant functions that are optimal in terms of differentiation between both groups are not necessarily the best predictors for unknown samples, because of obvious overfitting. Therefore, the number of variables was gradually diminished until a reasonable small number of components with sufficient predictive power remained. This reduction in components was reached by repeating the analysis from the original large dataset by leaving the least informative components out, one by one.

Statistical analysis of clinical data

Statistical analysis was performed using SPSS and Prism 5.0 (GraphPad Software Inc., San Diego, CA) for Windows. Differences between groups were analyzed by the Mann Whitney $U$ test or the Kruskal Wallis-test followed by Dunn's post-testing. A $p<0.05$ was considered statistically significant. Data are presented as mean \pm standard error of the mean.

\section{Results}

Population characteristics

The body mass index (BMI) ranged from 24.8 to $64.3 \mathrm{~kg} / \mathrm{m}^{2}$ (mean $43.7 \mathrm{~kg} / \mathrm{m}^{2}$ ), population characteristics are summarized in Table 1 . NASH was diagnosed in 39 subjects (60\%). The average plasma ALT and AST levels were higher in subjects with NASH 
Table 1. Characteristics of the study population.

\begin{tabular}{|c|c|c|}
\hline & Subjects without NASH & Subjects with $\mathrm{NASH}$ \\
\hline No. of patients & 26 & 39 \\
\hline Age (yr) & $45 \pm 2$ & $44 \pm 2$ \\
\hline Sex (M:F) & $8: 24$ & $14: 26$ \\
\hline BMI $\left(\mathrm{kg} / \mathrm{m}^{2}\right)$ & $41.0 \pm 1.3$ & $45.2 \pm 1.4$ \\
\hline $\mathrm{HbA}_{1 \mathrm{c}}(\%)$ & $6.4 \pm 0.3$ & $6.8 \pm 0.3$ \\
\hline $\mathrm{HT}(\mathrm{y} / \mathrm{n})$ & $10 / 22$ & $18 / 22$ \\
\hline CRP (mg/dl) & $6.0 \pm 0.44$ & $6.7 \pm 2.1$ \\
\hline ALT (IU/L) & $22.9 \pm 2.0$ & $29.6 \pm 2.5^{*}$ \\
\hline AST (IU/L) & $18.8 \pm 1.5$ & $27.1 \pm 2.2^{*}$ \\
\hline AST/ALT ratio & $0.9 \pm 0.1$ & $1.1 \pm 0.1$ \\
\hline
\end{tabular}

Data are presented as mean \pm SEM.

*ALT and AST levels differed significantly between the groups (for both $p<0.05$ ), whereas no significant differences were observed for all other parameters.

Table 2. Activity, stages and grades of NASH.

\begin{tabular}{|c|c|c|}
\hline BRUNT SCORE & & NASH subjects $(n=39)$ \\
\hline \multirow[t]{3}{*}{ Grade } & 1 & 19 \\
\hline & 2 & 18 \\
\hline & 3 & 2 \\
\hline \multirow[t]{4}{*}{ Stage } & 0 & 15 \\
\hline & 1 & 13 \\
\hline & 2 & 10 \\
\hline & 3 & 1 \\
\hline \multicolumn{2}{|l|}{ KLEINER SCORE } & NASH subjects $(n=39)$ \\
\hline \multirow[t]{4}{*}{ Steatosis } & Grade 0 & 0 \\
\hline & Grade 1 & 15 \\
\hline & Grade 2 & 21 \\
\hline & Grade 3 & 3 \\
\hline \multirow[t]{2}{*}{ Ballooning } & Grade 0 & 14 \\
\hline & Grade 1 & 25 \\
\hline \multirow[t]{4}{*}{ Lobular inflammation } & Grade 0 & 0 \\
\hline & Grade 1 & 30 \\
\hline & Grade 2 & 8 \\
\hline & Grade 3 & 1 \\
\hline \multirow[t]{4}{*}{ Fibrosis } & Stage 0 & 21 \\
\hline & Stage 1 & 11 \\
\hline & Stage 2 & 6 \\
\hline & Stage 3 & 1 \\
\hline
\end{tabular}

compared to subjects without NASH (Table 1). Importantly, parameters such as gender, age, $\mathrm{BMI}$, and $\mathrm{HbA}_{1 \mathrm{c}}$ did not differ significantly. The $39 \mathrm{NASH}$ patients were scored according to the scoring systems of Brunt and Kleiner; most subjects suffered from relatively mild NASH. As depicted in Table 2, the majority of

\section{JOURNAL OF HEPATOLOGY}

subjects categorized in grade 1 or 2 and in stage 0 or 1 according to Brunt, whereas according to the NAS activity score by Kleiner et al. most subjects showed steatosis grade 2 , ballooning grade 1 , lobular inflammation grade 1 , and no or little fibrosis.

\section{Assessment based on volatile organic compounds}

Analysis of VOC showed that subjects with NASH could be distinguished from those without NASH with a sensitivity of $90 \%$ and a specificity of $69 \%$, based upon a combination of three components. These three most discriminating compounds were (1) n-tridecane, (2) 3-methyl-butanonitrile and (3) 1-propanol as identified by means of their mass spectrum. When more components were taken into account, the prediction became more accurate, and as expected, when less compounds were taken into account, the specificity of breath analysis diminished accordingly (Fig 1A). The optimal relation between sensitivity and specificity was calculated at various cut-off values for the discriminant function, as visualized in the receiver operating characteristic (ROC) curve. For the three described components, the area under the curve was $0.77 \pm 0.07$ (Fig. 1B). In order to interpret the clinical value of this test, likelihood ratios (LR) and predictive values (PV) were calculated $[23,24]$. The positive LR is the probability that a positive test result actually reflects the presence of the disease. This was 2.90 for the three components (Table 3), whereas the negative LR, a measure of the probability that a negative test result reflects the absence of NASH, was 0.15 . The actual prevalence was taken into account by calculating the positive PV, the percentage of subjects with a positive test result who actually suffer from NASH, which was $81 \%$. The negative PV, the proportion of patients with a negative test result that do not suffer from NASH, was $82 \%$ (Table 3). If the decision to obtain a liver biopsy in our study population had been based upon the three mentioned components in exhaled breath, 43 patients would have been biopsied, of whom eight did not have NASH (19\%), while four subjects with NASH (10\%) would have been missed. In total, 12 out of the 65 subjects (18\%) would have been misdiagnosed.

\section{Assessment of NASH based on elevated plasma transaminase levels}

Currently, the decision to obtain a liver biopsy in clinical practice is largely based upon either elevated ALT levels or increased AST/ ALT ratio. In order to assess the clinical value of the breath test, we compared the obtained data to the predictive properties of our current clinical procedure. Hence, we calculated the proportion of the population that would have undergone a liver biopsy based upon plasma levels of transaminases. Plasma could not be obtained from four subjects (of whom two suffered from NASH and two did not), therefore the remaining 61 subjects were analyzed. If the indication to obtain a biopsy had been based upon elevated ALT levels, eight biopsies (of seven patients with and one without NASH) would have been obtained. Perhaps more importantly, 30 out of the 37 remaining subjects with NASH (81\%) would have been missed (Fig. 2). Increased ALT levels showed a sensitivity of $19 \%$ and a specificity of $96 \%$. The positive PV for increased ALT was $88 \%$ while the negative PV was $43 \%$ (Table 3).

Next, AST/ALT ratios were calculated. If a liver biopsy had been obtained from subjects with an increased AST/ALT ratio, 17 biopsies would have been performed; 12 of subjects with NASH and 5 of subjects without NASH. Moreover, 25 patients 
Research Article

A

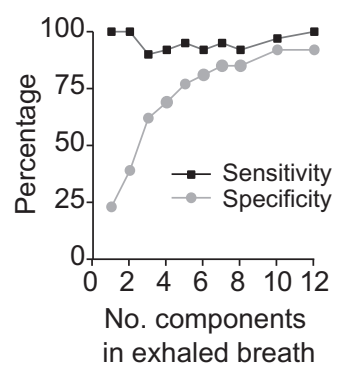

B

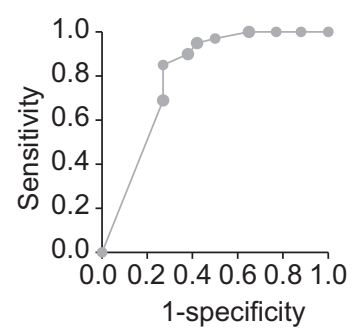

Fig. 1. Analysis of the number of breath components and ROC curve. (A) Sensitivity and specificity of exhaled breath related to the number of components incorporated in the discriminant function. With 1 or 2 components, the sensitivity of exhaled breath to predict NASH presence in overweight and obese subjects is $100 \%$ with a specificity of $23 \%$ and $39 \%$ respectively, whereas the optimum is with three components (sensitivity $90 \%$, specificity 69\%). (B) ROC curve for discriminant function based on $n$-tridecane, 3-methyl-butanonitrile, and 1-propanol, the area under the curve is $0.77 \pm 0.07$ (95\% CI 0.64-0.89).

or $68 \%$ of all subjects with NASH would have been missed (Fig. 2). The sensitivity of an increased AST/ALT ratio was $32 \%$, the specificity $79 \%$, the positive PV 70\%, and the negative PV 43\%, respectively (Table 3).

The consequences of assessing NASH presence based upon breath in comparison to plasma in the current study population are striking. The percentage of subjects that would have undergone liver biopsies based upon either VOC, increased plasma ALT, or AST/ALT ratio is depicted in Fig. 2. It can be concluded that the diagnostic value of VOC is much higher than that of plasma transaminases, resulting in less misdiagnosed patients. More specifically, the prediction did not match the actual histological hepatic evaluation in $18 \%$ of the subjects (12 out of 65 ) based upon VOC, in $51 \%$ based upon ALT (31 out of 61 ) and in $49 \%$ (30 out of 61) based upon AST/ALT ratio. The inconsistent predictive properties of plasma transaminases were further emphasized by the observation that only one patient had both elevated ALT levels and an increased AST/ALT ratio. Patients who were correctly identified with NASH by means of plasma parameters were also identified by means of the breath test. In addition, the breath test identified a considerable proportion of NASH patients with normal plasma parameters. In order to assess the potential additive value of considering other known risk factors, multivariate analysis was performed including BMI, age, gender, hypertension, apnea, and $\mathrm{HbA}_{1 \mathrm{c}}$, plasma ALT, AST, triglycerides, glucose, and insulin. Only the discriminative value of VOC reached statistical significance $(p<0.05)$, all other parameters did not show any additive value to predict NASH presence (Table 4).

Table 3. Test accuracy of VOC analyses and elevated plasma parameters.

\begin{tabular}{llll}
\hline & VOC & ALT & AST/ALT >1 \\
\hline Sensitivity & $90 \%$ & $19 \%$ & $32 \%$ \\
Specificity & $69 \%$ & $96 \%$ & $79 \%$ \\
Positive LR & 2.90 & 4.54 & 1.52 \\
Negative LR & 0.15 & 0.85 & 0.85 \\
Positive PV & $81 \%$ & $88 \%$ & $70 \%$ \\
Negative PV & $82 \%$ & $43 \%$ & $43 \%$ \\
\hline
\end{tabular}
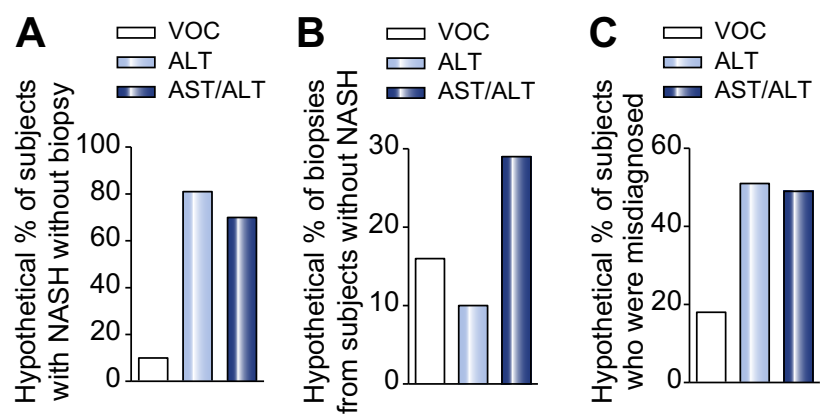

Fig. 2. Number of subjects who are (mis)diagnosed based upon breath or plasma transaminase levels. (A) Percentage of patients falsely predicted not to have NASH by VOC (4/39 or $10 \%$ ), increased ALT values (30/37 or $81 \%$ ), and increased AST/ALT ratio (25/37 or 68\%). (B) The percentage of obtained biopsies from patients without NASH would be $7 / 29(16 \%)$ for VOC, 1 out of $8(13 \%)$ for ALT, and 5 out of 17 (29\%) for AST/ALT, if the indication to obtain a biopsy had been based hereupon. (C) The percentage of misdiagnosed patients was 12/65 based upon VOC (18\%), 31/61 (51\%) based upon increased plasma ALT, and 30/61 (49\%) based upon AST/ALT ratio $>1$.

\section{Discussion}

In order to find a less invasive method to diagnose NASH, VOC in exhaled breath were examined in relation to the evaluation of wedge-shaped liver biopsies in a cohort of 65 overweight and obese subjects. The feasibility to predict the presence of NASH based upon three components in exhaled breath ( $n$-tridecane, 3-methyl-butanonitrile, and 1-propanol) was found to be high compared to plasma and clinical parameters. Moreover, by means of these three exhaled breath components, almost all of the subjects who would have been missed based upon plasma ALT and AST/ALT ratio, could be identified. The fact that many subjects are missed in case of risk assessment based upon ALT levels or AST/ALT ratio is supported by others. It has been shown previously that plasma aminotransferase levels do not correlate well with disease activity. For example, patients with NASH can still have normal AST/ALT ratios and normal transaminase levels despite advanced disease [11].

In order to enhance chances of cure and to prevent potential progression into fibrosis and cirrhosis, it is essential to diagnose NASH at an early stage, especially since recent longitudinal studies showed that patients with NASH already run a high risk to develop liver-related complications and to suffer from liverrelated mortality $[25,26]$. The Non-alcoholic Steatohepatitis Clinical Research Network recently stated that clinical and laboratory parameters are insufficient to reliably diagnose NASH [10]. However, given the associated discomfort, complications and costs, the burden of screening for this emerging liver disease by means of percutaneous liver biopsies would be disproportional to the benefit. The necessity to find minimal invasive cost-effective ways of screening will further intensify, given the rising incidence of obesity and NASH. Current research therefore focuses on less invasive methods to differentiate between the various stages of NAFLD. For example, plasma markers of epithelial cell damage, e.g., cytokeratin-18 and its fragments, are promising to assess NASH presence $[27,28]$. Radiological modalities such as ultrasonography [29] and transient elastography [30,31] may also assist in identifying subjects with NASH. Transient elastography (tissue elasticity measurement based on ultrasound technology) was found to aid in predicting the presence of fibrosis [30] and 
Table 4. Multivariate analysis.

\begin{tabular}{|c|c|c|c|c|}
\hline & $\beta$ & S.E. & Wald & $p$ value \\
\hline VOC & -1.296 & 0.645 & 4.034 & $0.045^{*}$ \\
\hline ALT & 0.005 & 0.052 & 0.009 & 0.926 \\
\hline AST & 0.094 & 0.071 & 1.767 & 0.184 \\
\hline $\operatorname{Sex}(M: F)$ & -0.147 & 1.276 & 0.013 & 0.908 \\
\hline Age (yr) & -0.021 & 0.056 & 0.145 & 0.979 \\
\hline BMI $\left(\mathrm{kg} / \mathrm{m}^{2}\right)$ & -0.074 & 0.117 & 0.397 & 0.529 \\
\hline $\mathrm{HbA}_{1 \mathrm{c}}(\%)$ & -1.210 & 1.193 & 1.029 & 0.310 \\
\hline Glucose & 1.373 & 0.991 & 1.922 & 0.166 \\
\hline Insulin & 0.061 & 0.075 & 0.654 & 0.419 \\
\hline TG & -0.510 & 0.749 & 0.464 & 0.496 \\
\hline $\mathrm{HT}(\mathrm{y} / \mathrm{n})$ & 0.142 & 1.030 & 0.019 & 0.890 \\
\hline Apnea (y/n) & 0.753 & 1.490 & 0.255 & 0.613 \\
\hline
\end{tabular}

${ }^{*}$ Only VOC shows statistical significance in multivariate analysis $(p<0.05)$. The $\beta$-coefficient reflects the importance of the parameter potentially predicting NASH presence, whereas the Wald value is used to test the true value of this importance; whether it is statistically significant. Apart from the volatile organic compounds, none of these parameters reached statistical significance; therefore none of them facilitate the diagnosis of NASH.

hepatic inflammation [31]. With respect to ultrasound, differentiation between steatosis and NASH is reported as challenging; its sensitivity diminishes even further in case of less than $40 \%$ hepatic steatosis [32]. In addition, the accuracy of radiological techniques is operator-dependent and subject to intra- and inter-observer variability [33].

The classical way to diagnose NASH, by means of histopathological examination of a percutaneous needle biopsy consisting of a tiny portion of the total liver mass (an estimated $1 / 50,000$ ), is vulnerable to variability [34]. To reduce this variability, relatively large wedge-shaped liver biopsies containing at least five portal tracts were used in this pilot study, allowing a thorough histological evaluation [35]. Occasionally, these biopsies may have been derived from a relatively more subcapsular region, in which fibrosis is more often detected than in needle biopsies of the deeper parenchyma. However, this emphasizes that analysis of exhaled breath can identify NASH presence at an early stage, and early identification in a mild stage is pivotal to enhance the chances of cure. Furthermore, whereas a small part of the liver is considered in the evaluation of biopsies, the breath test used in this study non-invasively reflects total liver function.

Previously, other breath tests have been used to indicate the extent of liver disease. For example, the so-called caffeine breath test was reported to predict the presence of hepatic fibrosis in a study of 48 subjects [36]. VOC analysis in exhaled breath has previously been used to discriminate between patients with and without inflammatory airway diseases $[13,14]$. Based upon findings in these studies, we here investigated the potential of VOC analysis to diagnose NASH, and to differentiate subjects with and without NASH in a high-risk population with relatively mild to moderate NASH, emphasizing the discriminative potential of exhaled breath. The three volatile breath components $n$-tridecane, 3-methyl-butanonitrile, and 1-propanol were strongly related to NASH presence, and the absence of NASH was more accurately predicted than by use of plasma transaminase levels. Even though the exact origin of these compounds still needs to be investigated, it is tempting to speculate that they are related to inflammatory processes and/or lipid peroxidation. On the

\section{JOURNAL OF HEPATOLOGY}

one hand, NASH is characterized by inflammation [4], and inflammation has also been found to be reflected by 1-propanol in pulmonary cancer [37]. On the other hand, NASH has been associated with lipid products $[3,38]$, which have also been detected in exhaled breath in the context of cardiac surgery [39].

Further studies will not only focus on the exact origin of these compounds, but also on validation of these data in an independent group of patients. The diagnostic value of this breath test may be further enhanced by a combination with other plasma markers (e.g., the previously mentioned epithelial damage markers cytokeratin-18 and its fragments). Analysis of breath could aid as a first line screening tool for NASH. In addition, it would be of interest to test the potential of VOC analysis to evaluate the effect of treatment of this serious and emerging liver disease. The current cornerstones of this treatment are lifestyle modifications [40] and bariatric surgery, whereas novel pharmacological therapies are under investigation [41]. Bariatric surgery has been shown to improve NAFLD in $92 \%$ and NASH in $81 \%$ of cases, and to induce complete remission of NASH in 69\% of cases [42]. Possibly, VOC analysis can be used to prioritize patients with NASH over those without NASH to undergo bariatric surgery. In conclusion, this pilot study indicates that analysis of exhaled breath can become a suitable non-invasive method to accurately predict which subjects suffer from NASH. This method has the potential to diminish the number of missed diagnoses of NASH.

\section{Financial support}

This research was supported by the Senter Novem Innovation Oriented Research Program on Genomics, grant IGE05012 and a Transnational University Limburg (TUL) grant.

\section{Conflict of interest}

The authors who have taken part in this study declared that they do not have anything to disclose regarding funding or conflict of interest with respect to this manuscript.

\section{Acknowledgements}

The authors thank Yanti Slaats for her contribution to the sample collection at the start of this study and Jelena Arsenijevic for her assistance in the statistical analyses.

\section{References}

[1] Angulo P. Obesity and nonalcoholic fatty liver disease. Nutr Rev 2007; 65:S57-S63.

[2] Vernon G, Baranova A, Younossi ZM. Systematic review: the epidemiology and natural history of non-alcoholic fatty liver disease and non-alcoholic steatohepatitis in adults. Aliment Pharmacol Ther 2011;34:274-285.

[3] Brunt EM. Pathology of fatty liver disease. Mod Pathol 2007;20 (Suppl 1):S40-S48.

[4] Tilg H, Moschen AR. Evolution of inflammation in nonalcoholic fatty liver disease: the multiple parallel hits hypothesis. Hepatology 2010;52: 1836-1846.

[5] Brunt EM, Janney CG, Di Bisceglie AM, Neuschwander-Tetri BA, Bacon BR Nonalcoholic steatohepatitis: a proposal for grading and staging the histological lesions. Am J Gastroenterol 1999;94:2467-2474.

[6] Kleiner DE, Brunt EM, Van Natta M, Behling C, Contos MJ, Cummings OW et al. Design and validation of a histological scoring system for nonalcoholic fatty liver disease. Hepatology 2005;41:1313-1321. 


\section{Research Article}

[7] Bravo AA, Sheth SG, Chopra S. Liver biopsy. N Engl J Med 2001;344:495-500.

[8] Piccinino F, Sagnelli E, Pasquale G, Giusti G. Complications following percutaneous liver biopsy. A multicentre retrospective study on 68,276 biopsies. J Hepatol 1986;2:165-173.

[9] Junior WS, Nonino-Borges CB. Clinical predictors of different grades of nonalcoholic fatty liver disease. Obes Surg 2012;22:248-252.

[10] Neuschwander-Tetri BA, Clark JM, Bass NM, Van Natta ML, Unalp-Arida A Tonascia J, et al. Clinical, laboratory and histological associations in adults with nonalcoholic fatty liver disease. Hepatology 2010;52:913-924.

[11] Mofrad P, Contos MJ, Haque M, Sargeant C, Fisher RA, Luketic VA, et al. Clinical and histologic spectrum of nonalcoholic fatty liver disease associated with normal ALT values. Hepatology 2003;37:1286-1292.

[12] Paredi P, Kharitonov SA, Barnes PJ. Analysis of expired air for oxidation products. Am J Respir Crit Care Med 2002;166:S31-S37.

[13] Dallinga JW, Robroeks CM, van Berkel JJ, Moonen EJ, Godschalk RW, Jobsis Q et al. Volatile organic compounds in exhaled breath as a diagnostic tool for asthma in children. Clin Exp Allergy 2010;40:68-76.

[14] Van Berkel JJ, Dallinga JW, Moller GM, Godschalk RW, Moonen EJ, Wouters $\mathrm{EF}$, et al. A profile of volatile organic compounds in breath discriminates COPD patients from controls. Respir Med 2010;104:557-563.

[15] Millonig G, Praun S, Netzer M, Baumgartner C, Dornauer A, Mueller S, et al Non-invasive diagnosis of liver diseases by breath analysis using an optimized ion-molecule reaction-mass spectrometry approach: a pilot study. Biomarkers 2010;15:297-306.

[16] Netzer M, Millonig G, Osl M, Pfeifer B, Praun S, Villinger J, et al. A new ensemble-based algorithm for identifying breath gas marker candidates in liver disease using ion molecule reaction mass spectrometry. Bioinformatics 2009;25:941-947.

[17] Solga SF, Alkhuraishe A, Cope K, Tabesh A, Clark JM, Torbenson M, et al. Breath biomarkers and non-alcoholic fatty liver disease: preliminary observations. Biomarkers 2006;11:174-183.

[18] Van Berkel JJ, Dallinga JW, Moller GM, Godschalk RW, Moonen E, Wouters $\mathrm{EF}$, et al. Development of accurate classification method based on the analysis of volatile organic compounds from human exhaled air. J Chromatogr B Analyt Technol Biomed Life Sci 2008;861:101-107.

[19] Verdam FJ, Greve JW, Roosta S, van Eijk H, Bouvy N, Buurman WA, et al. Small intestinal alterations in severely obese hyperglycemic subjects. J Clin Endocrinol Metab 2011;96:E379-E383.

[20] Dufour DR, Lott JA, Nolte FS, Gretch DR, Koff RS, Seeff LB. Diagnosis and monitoring of hepatic injury. I. Performance characteristics of laboratory tests. Clin chem 2000;46:2027-2049.

[21] Pratt DS, Kaplan MM. Evaluation of abnormal liver-enzyme results in asymptomatic patients. N Engl J Med 2000;342:1266-1271.

[22] Verdam FJ, Rensen SS, Driessen A, Greve JW, Buurman WA. Novel evidence for chronic exposure to endotoxin in human nonalcoholic steatohepatitis. J Clin Gastroenterol 2011;45:149-152.

[23] Bossuyt X. Clinical performance characteristics of a laboratory test. A practical approach in the autoimmune laboratory. Autoimmun Rev 2009;8:543-548.

[24] Camp BW. What the clinician really needs to know: questioning the clinical usefulness of sensitivity and specificity in studies of screening tests. J Dev Behav Pediatr 2006;27:226-230.

[25] Adams LA, Lymp JF, St Sauver J, Sanderson SO, Lindor KD, Feldstein A, et al The natural history of nonalcoholic fatty liver disease: a population-based cohort study. Gastroenterology 2005;129:113-121.
[26] Ekstedt M, Franzen LE, Mathiesen UL, Thorelius L, Holmqvist M, Bodemar G, et al. Long-term follow-up of patients with NAFLD and elevated liver enzymes. Hepatology 2006;44:865-873.

[27] Feldstein AE, Wieckowska A, Lopez AR, Liu YC, Zein NN, McCullough AJ. Cytokeratin-18 fragment levels as noninvasive biomarkers for nonalcoholic steatohepatitis: a multicenter validation study. Hepatology 2009;50: 1072-1078.

[28] Joka D, Wahl K, Moeller S, Schlue J, Vaske B, Bahr MJ, et al. Prospective biopsy-controlled evaluation of cell death biomarkers for prediction of liver fibrosis and nonalcoholic steatohepatitis. Hepatology 2012;55:455-464.

[29] Williams CD, Stengel J, Asike MI, Torres DM, Shaw J, Contreras M, et al. Prevalence of nonalcoholic fatty liver disease and nonalcoholic steatohepatitis among a largely middle-aged population utilizing ultrasound and liver biopsy: a prospective study. Gastroenterology 2011;140:124-131.

[30] Myers RP, Pomier-Layrargues G, Kirsch R, Pollett A, Duarte-Rojo A, Wong D, et al. Feasibility and diagnostic performance of the FibroScan XL probe for liver stiffness measurement in overweight and obese patients. Hepatology 2012;55:199-208

[31] Chen J, Talwalkar JA, Yin M, Glaser KJ, Sanderson SO, Ehman RL. Early detection of nonalcoholic steatohepatitis in patients with nonalcoholic fatty liver disease by using MR elastography. Radiology 2011;259:749-756.

[32] Mottin CC, Moretto M, Padoin AV, Swarowsky AM, Toneto MG, Glock L, et al. The role of ultrasound in the diagnosis of hepatic steatosis in morbidly obese patients. Obes Surg 2004;14:635-637.

[33] Strauss S, Gavish E, Gottlieb P, Katsnelson L. Interobserver and intraobserver variability in the sonographic assessment of fatty liver. AJR Am J Roentgenol 2007;189:W320-W323.

[34] Ratziu V, Charlotte F, Heurtier A, Gombert S, Giral P, Bruckert E, et al. Sampling variability of liver biopsy in nonalcoholic fatty liver disease. Gastroenterology 2005;128:1898-1906.

[35] Arun J, Jhala N, Lazenby AJ, Clements R, Abrams GA. Influence of liver biopsy heterogeneity and diagnosis of nonalcoholic steatohepatitis in subjects undergoing gastric bypass. Obes Surg 2007;17:155-161.

[36] Park GJ, Wiseman E, George J, Katelaris PH, Seow F, Fung C, et al. Noninvasive estimation of liver fibrosis in non-alcoholic fatty liver disease using the (13) C-caffeine breath test. J Gastroenterol Hepatol 2011;26:1411-1416.

[37] Ligor M, Ligor T, Bajtarevic A, Ager C, Pienz M, Klieber M, et al. Determination of volatile organic compounds in exhaled breath of patients with lung cancer using solid phase microextraction and gas chromatography mass spectrometry. Clin Chem Lab Med 2009;47:550-560.

[38] Seki S, Kitada T, Yamada T, Sakaguchi H, Nakatani K, Wakasa K. In situ detection of lipid peroxidation and oxidative DNA damage in non-alcoholic fatty liver diseases. J Hepatol 2002;37:56-62.

[39] Pabst F, Miekisch W, Fuchs P, Kischkel S, Schubert JK. Monitoring of oxidative and metabolic stress during cardiac surgery by means of breath biomarkers: an observational study. J Cardiothorac Surg 2007;2:37.

[40] Lebovics E, Rubin J. Non-alcoholic fatty liver disease (NAFLD): why you should care, when you should worry, what you should do. Diabetes Metab Res Rev 2011;27:419-424.

[41] Zein CO, Yerian LM, Gogate P, Lopez R, Kirwan JP, Feldstein AE, et al. Pentoxifylline improves nonalcoholic steatohepatitis: a randomized placebo-controlled trial. Hepatology 2011;54:1610-1619.

[42] Mummadi RR, Kasturi KS, Chennareddygari S, Sood GK. Effect of bariatric surgery on nonalcoholic fatty liver disease: systematic review and metaanalysis. Clin Gastroenterol Hepatol 2008;6:1396-1402. 